\title{
Naturally Occurring Cell Death and Differentiation of Developing Spinal Motoneurons Following Axotomy
}

\author{
Paul B. Farel \\ Department of Physiology, School of Medicine, University of North Carolina, Chapel Hill, North Carolina 27599
}

\begin{abstract}
The purpose of this study was to examine the effects of axon transection on the development and differentiation of spinal motoneurons in the bullfrog (Rana catesbeiana) tadpole. The 3 ventral roots (VRs) that innervate the hindlimb were transected, and the animals were killed 6-7 weeks later (reinnervation took place within 3 weeks). At early stages of development, axotomy resulted in an increase in the number of spinal motoneurons on the operated side. By histological criteria, these motoneurons appeared more differentiated than those in normal tadpoles. Axotomy was effective in increasing motoneuron number only during the period of naturally occurring cell death. Similar effects were seen when the transected VRs were ligated to prevent regeneration. Hindlimb amputation without VR transection had no effect on motoneuron number or differentiation. Thus, target removal is neither a necessary nor a sufficient condition for hyperplasia of the lateral motor column.
\end{abstract}

An extreme loss of spinal motoneurons was seen if the operated tadpole entered into metamorphic climax during the 6-7-week postoperative survival period. Motoneuron loss occurred although the injured motoneurons had reconnected to the hindlimb. In contrast, tadpoles allowed to survive up to 6 months showed no loss of motoneurons if they did not enter metamorphic climax.

From these data, it appears axon transection in developing spinal motoneurons exerts its effects on motoneuron number and differentiation by altering the metabolic state of the motoneuron (axon reaction) rather than by depriving it of contact with its target.

Limb amputation during early stages of motoneuron development in chick or frog leads to a profound loss of spinal motoneurons (Vulpian, 1868; von Gudden, 1870; Shorey, 1909; Detwiler, 1933; May, 1933; Hamburger, 1934, 1958) around the time of naturally occurring cell death (Beaudoin, 1955; Hughes, 1961; Prestige, 1967; Hamburger, 1975; Decker, 1978). Motoneuron death following amputation is usually attributed to the loss of access to limb-derived trophic factors at stages when motoneurons are dependent upon these factors for survival (Landmesser, 1980; Oppenheim, 1981; Purves and Lichtman, 1985). However, in frog, prior to this amputation-induced loss,

\footnotetext{
Received Aug. 22, 1988; revised Oct. 14, 1988; accepted Nov. 3, 1988.

I wish to acknowledge the skilled assistance of Ms. Sibyl (Bemelmans) Wray in completing this study. Ms. Carol Metz and R. Kirk McNaughton provided expert histological assistance. Supported by USPHS grant NS16030, with facilities support by USPHS grant 14899

Correspondence should be addressed to Paul B. Farel, Department of Physiology $\mathrm{CB} \# 7545$, School of Medicine, University of North Carolina, Chapel Hill, NC 27599.

Copyright (C) 1989 Society for Neuroscience $0270-6474 / 89 / 062103-11 \$ 02.00 / 0$
}

there is a paradoxical increase in motoneuron number on the operated side (Beaudoin, 1955; Hughes, 1961; Prestige, 1967; Decker, 1978).

Limb amputation performed after axonal outgrowth, in addition to removing a possible source of trophic support, also injures motoneurons by truncating their axons. Axotomy and the subsequent regenerative response cause profound changes in virtually every aspect of motoneuron functioning (Lieberman, 1971; Grafstein, 1975; Watson, 1976). The question then arises whether the effects attributed to loss of the target in frog are, at least in part, a consequence of injury to the cell rather than loss of access to a limb-derived trophic factor.

The bullfrog tadpole offers important advantages for answering this question. Its large size makes surgical manipulations possible from the earliest stages of motoneuron differentiation. In addition, larval development is extremely protracted in bullfrog (1-3 years; Dickerson, 1969; Viparina and Just, 1975), permitting events to be more precisely resolved in time than in faster-developing species. Thus, possible causal relations based on observations of temporal contiguity are more easily evaluated in bullfrog than in faster-developing animals, such as the anurans Xenopus laevis and Rana pipiens or chick.

The major findings of this study are: (1) Temporary disconnection of motoneurons from the hindlimb by transection of the ventral roots (VRs) leads to hyperplasia of the lateral motor column (LMC) on the operated side; (2) extreme loss of motoneurons occurs only if operated tadpoles advance into metamorphic climax during the postoperative period; (3) this loss occurs despite reconnection to the hindlimb and is not temporally related to the period of naturally occurring cell death; (4) hindlimb amputation alone has no effect on motoneuron number or state of motoneuron differentiation.

\section{Materials and Methods}

Animals. Bullfrog (Rana catesbeiana) tadpoles were obtained from Carolina Biological Supply (Burlington, NC) and Wm. A. Lemberger Co. (Oshkosh, WI). Animals were classified by developmental stage according to the criteria of Taylor and Kollros (1946) for R. pipiens. According to this scheme, tadpoles are staged primarily on the basis of hindlimb morphology, beginning with the onset of independent feeding at stage I. Stages I-V are limb bud stages; foot paddle stages extend from VI to X. During the premetamorphic stages (XI -XVII), the hindlimb becomes progressively larger and is of more use to the animal for swimming and pushing against obstacles. Stages XVIII-XXV, the metamorphic stages, begin with degeneration of the cloacal tailpiece. The forelimbs emerge at stage XX (defined as metamorphic climax), and the tail undergoes progressive degeneration until it is completely resorbed at stage XXV.

The effects of ventral rhizotomy were first noticed in the course of another study (Farel and Bemelmans, 1986). Eighteen of the 32 rhizotomized tadpoles older than stage XII at death described in the present paper were included in the earlier work. In addition, 10 of the tadpoles 
in which VRs were ligated are also reported upon in another context (Farel and Wray, 1989).

Unlike the situation in chick, in which innervation occurs after limb musculature is fairly well differentiated (Heaton, 1977), the first axons invade the hindlimb in bullfrog while the limb bud is still histologically homogeneous (stage III; Letinsky, 1974). Stage IV tadpoles were the youngest available from suppliers. Consequently, all the operations reported here occurred after substantial innervation of the hindlimb.

Surgical procedures. Tadpoles were anesthetized by immersion in $0.02 \%$ ethyl m-aminobenzoate (MS-222, Sigma). Following a dorsal laminectomy over the cauda equina, dorsal roots (DRs) were gently deflected with a glass probe, and VRs deriving from segments 8,9 , and 10 [numbered following the system of Gaupp (1896-1904), according to which the hindlimb is innervated by these 3 VRs] were transected with finc scissors. The cut cnds of the roots were separated, providing assurance that the transection was complete. No attempt was made to appose the cut ends of the roots. Animals in which the DRs were inadvertently stretched or cut were discarded.

In one group of 15 tadpoles, regeneration of VRs 8 and 9 was prevented by placing double ligatures of 11-0 suture on the proximal stumps of the severed roots. The cut ends of the root were then separated as far as possible. In a few instances, the small size of VR 8 made it possible to apply only one suture.

Another group of 27 tadpoles received large applications of HRP at several sites in the thigh in order to determine when reinnervation of the hindlimb occurred. HRP was recrystalized onto insect pins that were inserted into the hindlimb after the tissue was disrupted with fine forceps (Farel and Bemelmans, 1985, 1986).

Histological procedures. Following a 6-7-week survival period, tadpoles were anesthetized and perfused intracardially with $3 \%$ glutaral-

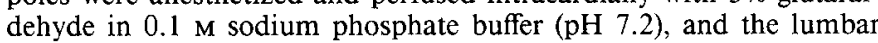
enlargement of the spinal cord was removed. The tissue was postlixed in the same solution for $24 \mathrm{hr}$, rinsed in phosphate buffer, dehydrated in ethanol, and embedded in paraffin for serial sections or in methacrylate. Tissue was sectioned at 5 or $6 \mu \mathrm{m}$ for tadpoles younger than stage VIII and at $8 \mu \mathrm{m}$ for older tadpoles. The lumbar enlargements of postmetamorphic frogs were sectioned at $10 \mu \mathrm{m}$. Paraffin sections were stained with thionin, and methacrylate sections were stained with toluidine.

Tissue from tadpoles that had received HRP applications was reacted en bloc with diaminobenzidine and embedded in paraffin according to previously described procedures (Farel and Bemelmans, 1985).

Counting procedurcs. Cytological characteristics relevant to counting change over development (Farel, 1987). At early stages of development, the nuclei of most motoneurons lack a defined nucleolus and instead have clumps of basophilic material (Fig. 1). As development proceeds, motoneurons of this type are less apparent, and the frequency of motoneurons typical of the adult increases. The nuclei of these matureappearing motoneurons contain a single, well-defined nucleolus. For less differentiated (type-L) profiles, a motoneuron was counted if at least 3 distinct basophilic clumps could be seen within the nucleus. For more differentiated (type-M) profiles, motoneurons were counted if a nucleolus could be identified. Nuclear and nucleolar diameters were measured at the caudal border of the entry zone of each of the lumbar roots. All profiles meeting the criteria to be counted were measured in 1-3 sections taken from each entry zone. This procedure resulted in measurements of at least 50 profiles on each side of each animal.

At early stages of development, both type- $\mathrm{L}$ and type-M motoneurons can be retrogradely labeled with HRP from either the hindlimb or the VR. As development proceeds, fewer type-L profiles can be labeled from the target; however, type-L profiles still can be labeled from the VR until metamorphic climax (Farel, 1987). These data provide assurance that type- $L$ profiles are indeed motoneurons.

Separate factors to correct for double counts were computed for each class of profile following Konigsmark's (1970) modification of Abercrombie's (1946) formula. Among tadpoles, correction factors ranged from .38 to .63 for type-L profiles and from .67 to .84 for type-M profiles. In 72 of 81 animals in which motoneurons were counted following VR transection, both sets of correction factors were within $5 \%$ of each other on the 2 sides. The remaining tadpoles had correction factors within $10 \%$ of each other. Motoneurons were counted in alternate sections and the totals doubled. All data are reported on counts corrected in this way.

Counting procedures were those previously used (Farel, 1987). Because the LMC at its poles is not easily distinguishable from the mantle zone in young animals, motoneurons were counted only in the region of the LMC between the caudal borders of DRs 8 and 10. This procedure has the potential disadvantage that motoneuron pools do not have a constant position relative to root entry zones (Cruce, 1974). However, this disadvantage is unlikely to introduce a systematic error and is outweighed by the advantage of allowing counts to be compared over the entire range of development.

Statistical significance was tested using Student's $t$ test (2-tailed) at the 0.05 level.

\section{Results}

Regeneration of motor axons

VR transection disconnects motoneurons from their targets; however, this condition persists only until the severed axons regrow to the hindlimb. To determine how long the motoneurons were disconnected from their targets, 27 tadpoles received large HRP applications in the proximal limb segment 13-28 d following VR transection. None of the 9 tadpoles from stages IV-VIII that received HRP $13 \mathrm{~d}$ after rhizotomy had retrogradely labeled motoneurons. However, all but one of the tadpoles (stages IV-XVI) that received HRP 16 or more d postoperatively had abundant labeled motoneurons. Thus, motoneuron axons regenerated to the hindlimb within 3 weeks of ventral rhizotomy.

\section{Effects of VR transection on motoneuron number}

Transection of VRs in tadpoles led to one of 2 outcomes, depending on whether the tadpole advanced beyond stage $\mathrm{XX}$ during the 6-7-week postoperative survival period. Tadpoles that did not reach stage XX during the postoperative survival period showed an increase in motoneuron number that depended on the stage at the time of VR transection. An example of one such tadpole that was operated on at stage VI and killed at stage VIII is shown in Figure 1. As can be seen in the higher power micrographs of the LMC, the operated side (Fig. 1C) shows a substantial increase in the number of motoneurons.

In contrast, Figure 2 illustrates a section taken from an animal operated on at stage XVII and killed as a juvenile frog 6 weeks later. In this animal, the number of motoneurons on the operated side is substantially reduced from that seen on the unoperated side, although the postoperative survival time was the same as that for the tadpole shown in Figure 1. Operated tadpoles that advanced beyond stage $\mathrm{XX}$ often showed evidence of degenerating motoneurons (Fig. 2C). The loss of motoneurons in this tadpole is unlikely to be related to the normal process of naturally occurring cell death, which is over by stage XI (Farel, 1987).

\section{Comparison with normal tadpoles}

Effect of rhizotomy on total motoneuron number. Figure 3 shows the number of motoneurons found on the 2 sides of the spinal cord 6-7 weeks following ventral rhizotomy plotted against stage at death. Individual values are represented by filled or open circles. Mean values and 95\% confidence intervals obtained from normal tadpoles are represented by the solid and dotted lines, respectively (from Farel, 1987). The differences in the mean numbers of motoneurons on the operated side and values obtained in normal tadpoles are statistically significant at each stage through stage $X$, except for stage VII, where the difference failed to reach significance $(0.05<p<0.1)$. No differences in motoneuron number were found after stage $X$. In contrast, mean motoneuron number on the unoperated side is not significantly different from that seen in normal tadpoles at any stage. Thus, 

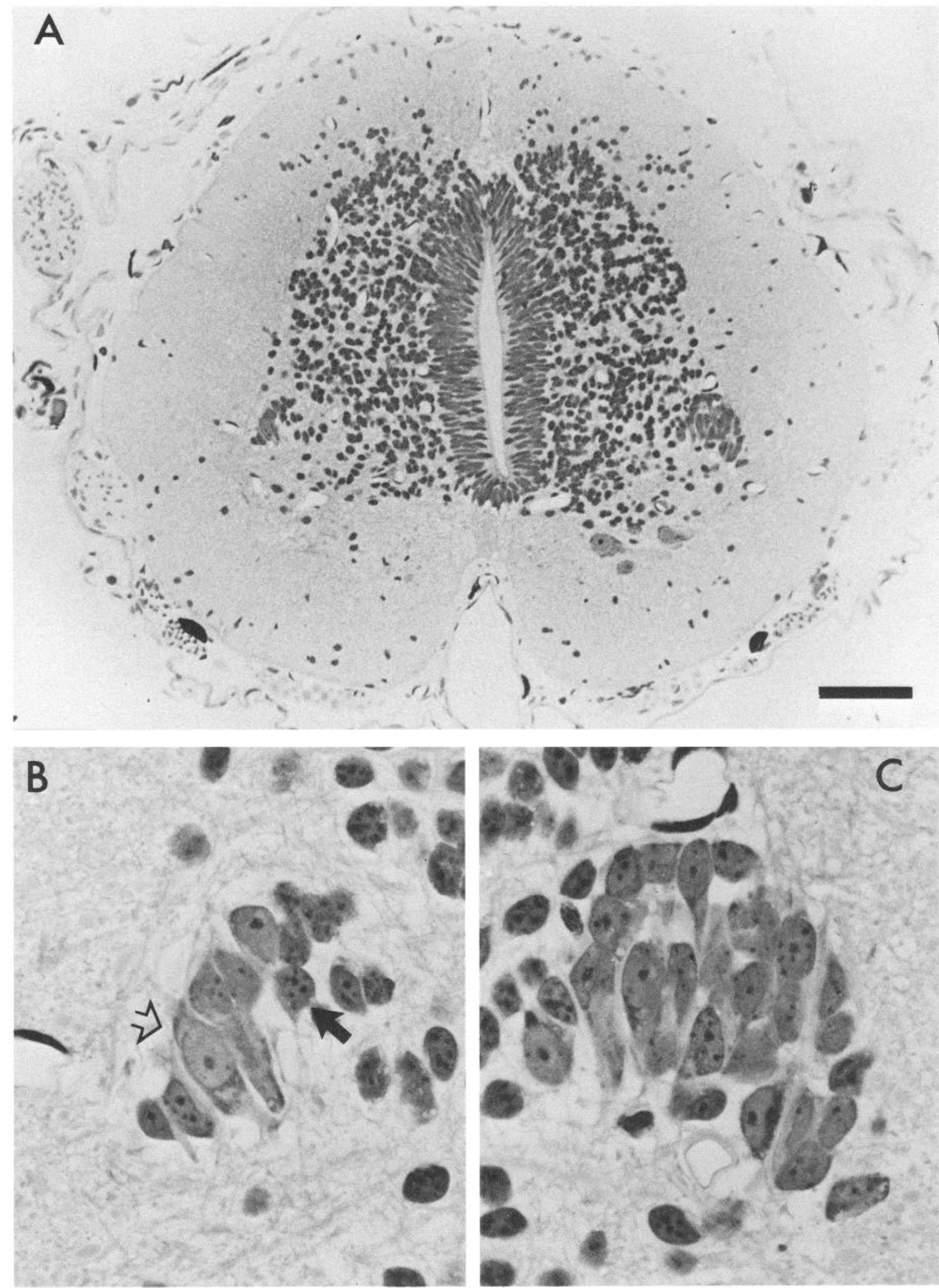

Figure 1. A, Low-power micrograph of a cross-section through the lumbar spinal cord of a stage VIII tadpole whose lumbar VRs were transected 6 weeks previously on the right side at stage VI. $B, C$, Higher-power micrographs of the LMCs on the unoperated $(B)$ and operated $(C)$ sides. The open and closed arrows in $(B)$ indicate type-M and type-L profiles, respectively. Note the greater number of motoneurons on the operated side. Scale bar: $A, 85 \mu \mathrm{m} ; B, C, 15 \mu \mathrm{m}$. 

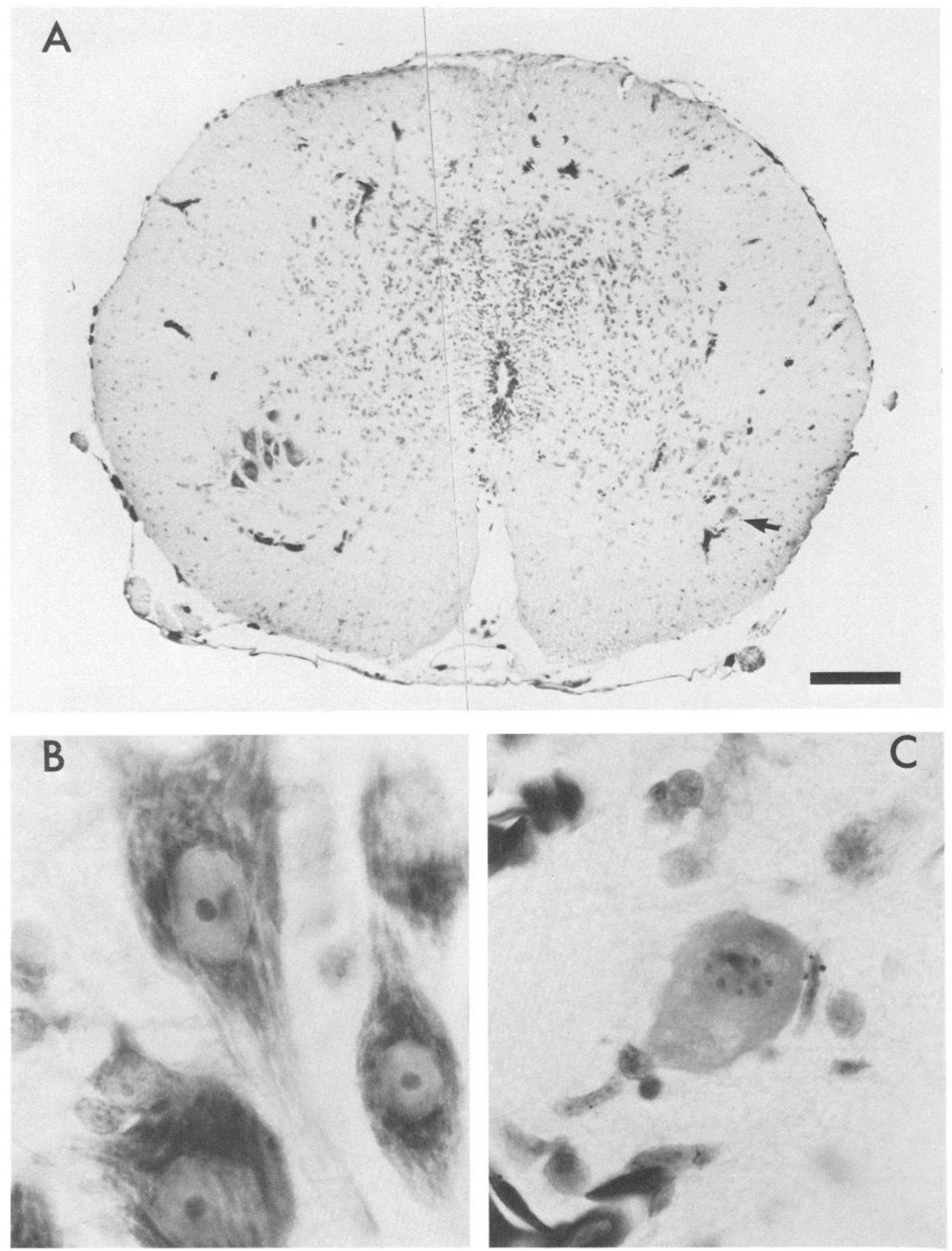

Figure 2. A, Low-power micrograph of a cross-section through the lumbar spinal cord of a juvenile frog whose lumbar VRs were transected on the right side 6 weeks previously at stage XVIII. Note the hypoplasia on the operated side. Arrow indicates an apparently degenerating motoneuron shown at higher power in $C . B, C$, Higher-power micrographs of the LMCs on the unoperated $(B)$ and operated $(C)$ sides. Scale bar: $A, 100 \mu$ m; $B, C, 10 \mu \mathrm{m}$. 


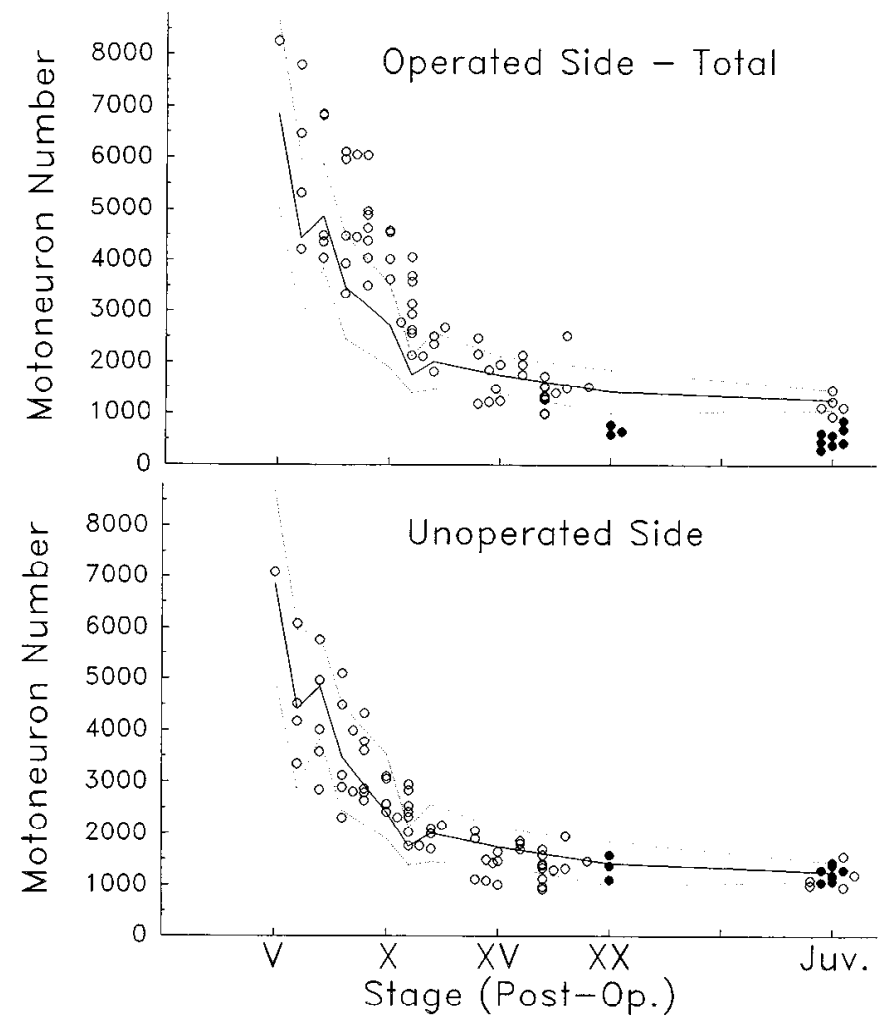

Figure 3. Total motoneuron number on the operated (top) and unoperated (bottom) sides of tadpoles subjected to transection of VRs 810 and allowed to survive 6-7 weeks. Motoneuron number is plotted against the stage at death. Solid line indicates mean values obtained in a study of normal tadpoles (Farel, 1987). Dotted lines indicate $\pm 95 \%$ confidence intervals for normal values. Solid circles represent animals operated on as tadpoles and killed after onset of metamorphic climax. Open circles represent animals killed before climax.

motoneuron number is increased by ventral rhizotomy on the operated side, but motoneuron number is unchanged on the intact side. This lack of a contralateral effect is in contrast to the results of Kett and Pollack (1985), who found that hindlimb amputation in $R$. pipiens increased motoneuron number on the unoperated side, although to a lesser degree than found ipsilaterally.

The stages when motoneuron number is increased by ventral rhizotomy correspond to the developmental period when the processes of naturally occurring cell death are operating (prior to stage XI; Farel, 1987). This finding is consistent with the conclusion derived from studies of hindlimb amputation that motoneuron number is increased by sparing some motoneurons from cell death (Beaudoin, 1955; Hughes, 1961; Prestige, 1967; Hamburger, 1975). Alternatively, axotomy could increase the rate of proliferation; however, this possibility is not consistent with the failure to find labeled motoneurons when ${ }^{3} \mathrm{H}$-thymidine was injected throughout the postoperative survival period (Farel and Bemelmans, 1986).

Motoneuron number was not reduced by prior axotomy unless metamorphic climax (emergence of the forelimbs from the body wall at stage $\mathrm{XX}$ ) occurred during the 6-7-week postoperative survival period (filled circles). This injury-induced motoneuron loss will be discussed below.

Effect of rhizotomy on motoneuron differentiation. Two classes of motoneurons can be identified in the LMC of tadpoles (Fig.

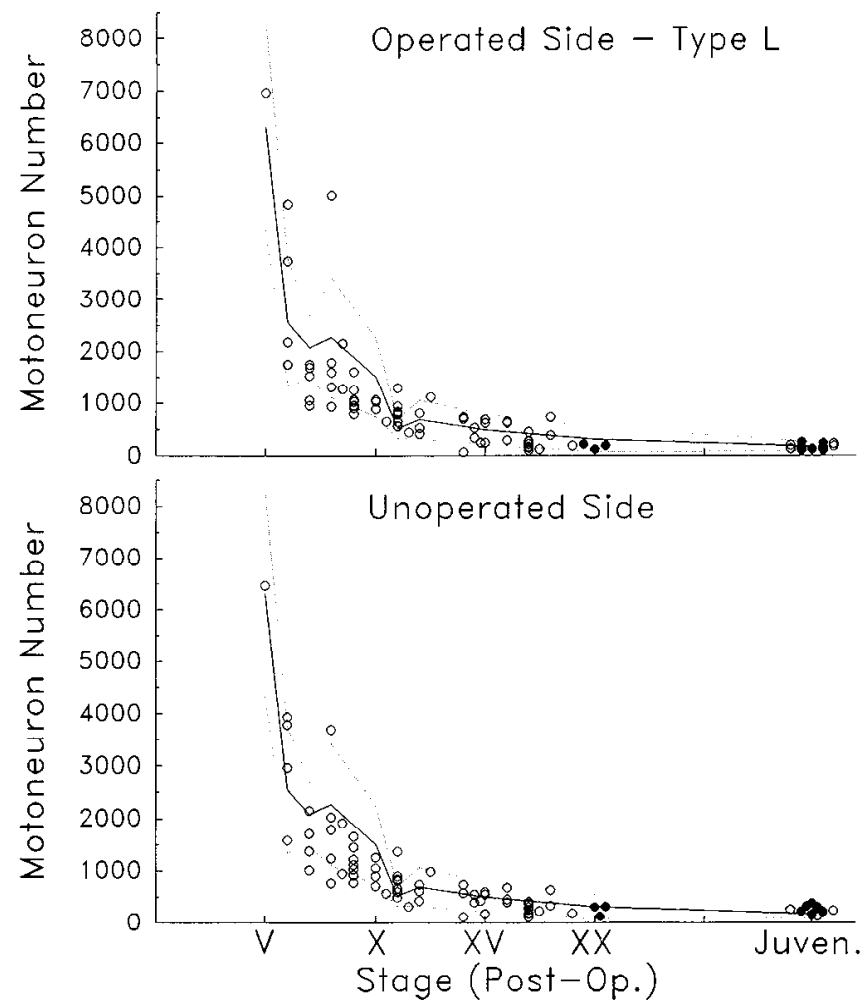

Figure 4. Type-L motoneuron number on the operated (top) and unoperated (bottom) sides of tadpoles subjected to transection of VRs 810 and allowed to survive 6-7 weeks. Motoneuron number is plotted against the stage at death. Solid line indicates mean values obtained in a study of normal tadpoles (Farel, 1987). Dotted lines indicate $\pm 95 \%$ confidence intervals for normal values. Solid circles represent animals operated upon as tadpoles and killed after onset of metamorphic climax. Open circles represent animals killed before climax.

1). Members of each class can be retrogradely labeled with HRP from the hindlimb or VR (Farel, 1987). Type-M motoneurons are characterized by a single large nucleolus and relatively abundant cytoplasm. Type-L motoneurons typically have only a thin rim of cytoplasm and, instead of a defined nucleolus, clumps of basophilic material within the nucleus. The proportion of type$\mathrm{L}$ motoneurons declines and that of type-M motoneurons increases as development proceeds (Farel, 1987). The effects of rhizotomy on the numbers of type-L and type-M motoneurons are shown in Figures 4 and 5 , respectively. Prior to stage $X$, most of the preparations had fewer type-L motoneurons on both the operated and the unoperated sides of the spinal cord than the mean value obtained in normal tadpoles. However, Student's $t$ tests comparing the mean number of type-L motoneurons at each stage with that obtained from normal tadpoles failed to reach statistical significance except at stage VII, where the number of type- $\mathrm{L}$ motoneurons on the operated side was significantly less than that found in normal tadpoles. Although these differences failed to reach significance on the unoperated side, the possibility exists that these data reflect a weak contralateral effect of ventral rhizotomy.

Although the effects of axotomy on type- $\mathrm{L}$ motoneuron number are fairly inconsequential, a substantial increase in the number of type-M motoneurons is seen during the period of naturally occurring ceil death (Fig. 5). This increase in more differentiated profiles accounts for the augmentation in total motoneuron number. The axotomy-induced shift of motoneurons to a more 


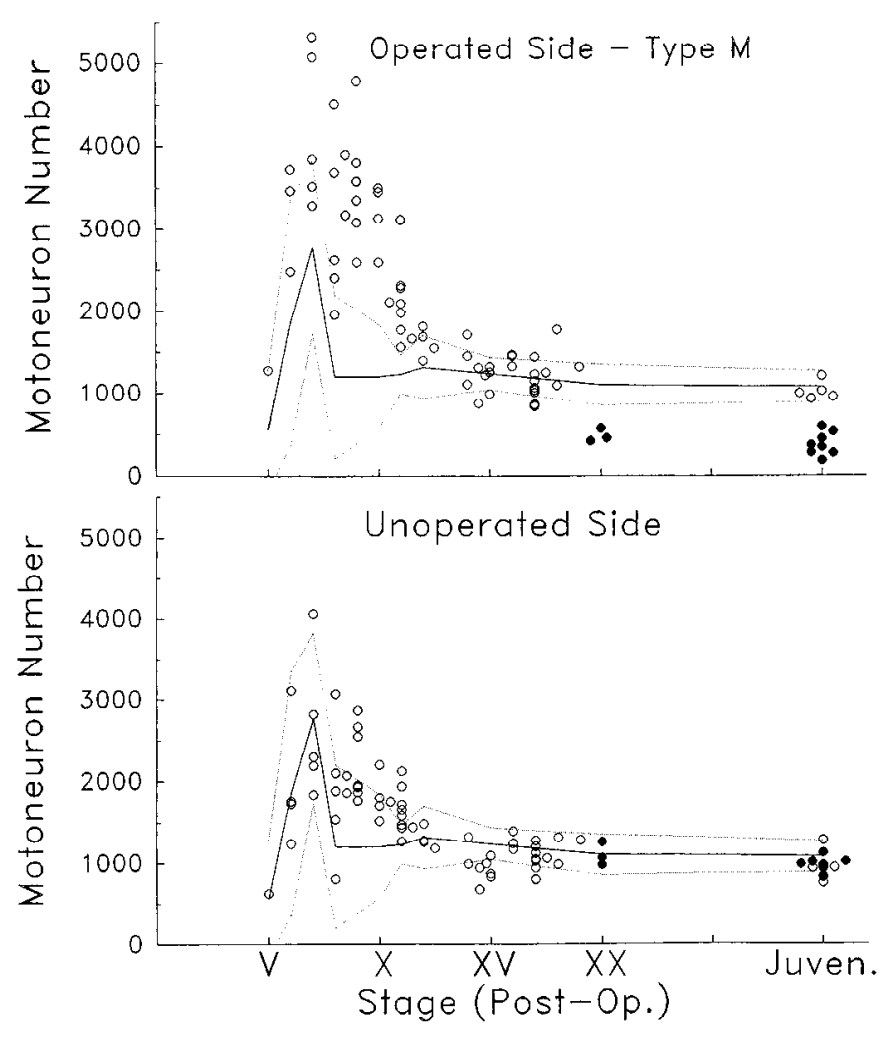

Figure 5. Type-M motoneuron number on the operated (top) and unoperated (bottom) sides of tadpoles subjected to transection of VRs 810 and allowed to survive 6-7 weeks. Motoneuron number is plotted against the stage at death. Solid line indicates mean values obtained in a study of normal tadpoles (Farel, 1987). Dotted lines indicatc $\pm 95 \%$ confidence intervals for normal values. Solid circles represent animals operated upon as tadpoles and sacrificed after onset of metamorphic climax. Open circles represent animals killed before climax.

differentiated appearance stands in contrast to findings obtained in $R$. pipiens, in which axotomy was reported to dclay motoneuron differentiation (Beaudoin, 1955; Kett and Pollack, 1985).

\section{Comparison of operated and unoperated sides}

Considerable variability is seen in motoneuron number, even in normal tadpoles (Farel, 1987; Sperry, 1987). By plotting the ratio of motoneurons on the operated and the unoperated sides, the effects of intrasubject variability can be reduced. Figure 6 shows the postoperative ratios for type-M, type-L, and total motoneuron number plotted as a function of preoperative (upper row) and postoperative (lower row) stage. For animals that did not develop to stage XX during the postoperative survival period (open circles), a clear stage-dependent effect of rhizotomy can be seen on ratios of type-M and total motoneuron numbers, whether data are plotted as a function of pre- or postoperative stage. However, the ratio of type-L motoneurons is not systematically affected by rhizotomy.

The unusual effect produced in tadpoles that developed beyond stage $\mathrm{XX}$ during the $6-7$-week postoperative survival period (filled circles) is shown in Figure 6. Each of the 10 tadpoles in this category was operated on at stages after motoneuron number has stabilized in normal animals (Farel, 1987). From the upper row, it can be seen that tadpoles operated on at the same slage do not show substantial motoneuron loss unless they advance beyond stage $\mathrm{XX}$ during the postoperative survival period. From the lower row, it is clear that death at an advanced stage is not the determining variable. For example, axotomized juvenile frogs (open circles) showed no evidence of motoneuron loss, but juvenile frogs that underwent rhizotomy as tadpoles (filled circles) showed substantial loss.

\section{Long-term survival following axotomy}

The results described thus far show that developing motoneurons do not die following disconnection from the hindlimb unless they enter into metamorphic climax during the 6-7-week postoperative survival period. Motoneuron death following axotomy thus appears to be a stage-dependent rather than a timedependent process. To test this possibility further, 4 stage $\mathrm{V}$ tadpoles were rhizotomized, allowed to survive for 6 months, and killed. The tadpoles ranged from stage $V$ to stage VII at death. The mean operated/unoperated ratios ( \pm SEM) of type$\mathrm{M}$, type-L, and total motoneurons were, respectively, $1.49 \pm$ $0.2,1.19 \pm 0.09$, and $1.26 \pm 0.1$. Thus, motoneuron number following ventral rhizotomy remains elevated for up to 6 months, providing support for the hypothesis that motoneuron death after rhizotomy depends on the developmental state of the tadpole rather than the postoperative time elapsed.

\section{Comparison of hindlimb amputation and ventral rhizotomy}

Ventral rhizotomy increases the number of motoneurons in the lumbar enlargement, but this increase may be the result of temporary disconnection from the hindlimb or from damage to the proximal motoneuron axons. To distinguish between these possibilities, 6 stage VIII tadpoles were subjected to unilateral hindlimb amputation (HLA). These data are shown in Figure 7 together with data from normal stage VIII tadpoles (from Farel, 1987) and from stage VIII tadpoles that had undergone ventral rhizotomies (VRT). Hindlimb amputation had no substantial effect on motoneuron number or on the proportion of type-M and type-L motoneurons. Because amputation removed the distal portions of motor axons, these data also show that motoneuron axotomy per se is not sufficient to trigger the changes leading to an increase in motoneuron number on the operated side.

A fourth group of stage VIII tadpoles underwent both amputation of the hindlimb and VR transection (HLA + VRT) in order to confirm that motoneuron number would increase in the absence of the hindlimb. These tadpoles showed an even greater increase than when ventral root transection was performed alone. The difference in motoneuron number between tadpoles that underwent ventral root transection alone and combined with amputation is statistically significant for the type-M category. The reasons for this difference are not clear, but, given the small numbers of tadpoles (5-7) in each group, sampling error is a likely source of this difference.

\section{Effects of preventing motor axon regeneration}

Reinnervation of the hindlimb takes place within 3 weeks of VR transection. The purpose of the following series of experiments was to determine the effect on motoneuron survival of blocking hindlimb reinnervation for the duration of the postoperative survival period. Following transection of VRs 8, 9, and 10 in 15 tadpoles, VRs 8 and 9 were ligated to prevent regeneration. The technical difticulty of this procedure prevented the ligation of all 3 VRs. Because the poles of the LMC were excluded from analysis, most of the motoneurons that were in the region of analysis were those whose axons were ligated. 

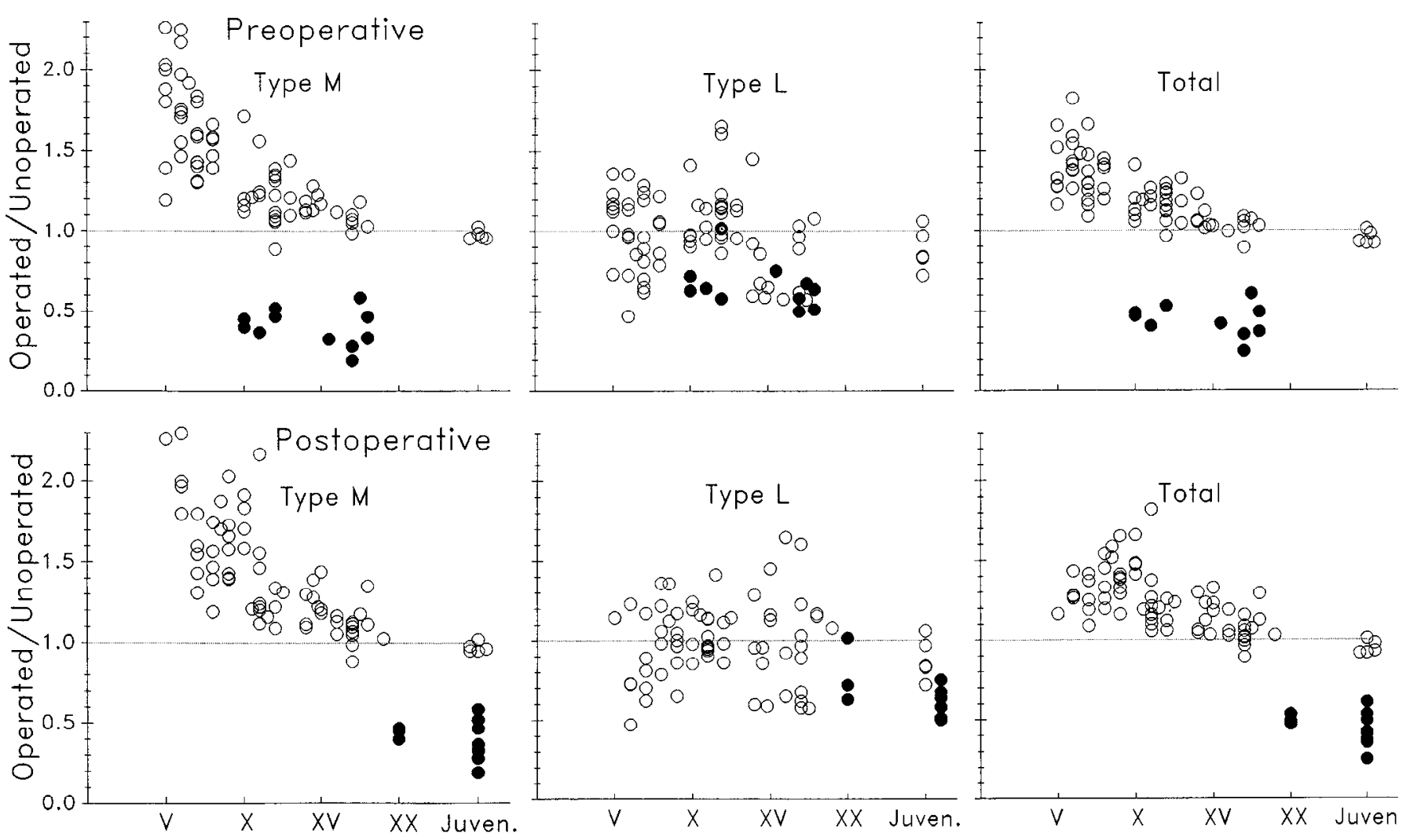

Figure 6. Postoperative ratios of motoneurons on the operated and unoperated sides of the spinal cord plotted against preoperative (upper row) and postoperative (lower row) stage. Graphs are presented for type-M (left), type-L (center), and total (right) motoneurons. Filled circles represent animals that were operated on as tadpoles and killed after entering metamorphic climax. Open circles represent animals killed before climax.

The efficacy of the ligation was confirmed by the virtual absence of retrogradely labeled motoneurons when HRP was placed in limb regions normally innervated by the ligated roots. A comparison of the number of retrogradely labeled motoneurons in these animals with data obtained from normal tadpoles (Farel and Bemelmans, 1985) shows that the thigh receives only 6-8\% of its normal innervation following ligation of VRs 8 and 9 (Farel and Wray, 1989).

Transection followed by ligation typically had the same effect as transection alone, increasing motoneuron number and the proportion of type-M profiles (Fig. 8). Cumulative results of these experiments are shown in Figure 9, in which ratios on the operated and unoperated sides are plotted against postoperative stage. Although the numbers are too few for quantitative comparisons, these data show that the increase in motoneuron number occurs when reinnervation of the hindlimb is prevented (open circles). Further, the loss of motoneurons in tadpoles that advance to metamorphic climax during the postoperative survival period also takes place when motoneuron axons are ligated following transection to prevent regeneration (closed circles).

Motoneuron numbers on the unoperated sides of these tadpoles were within the normal ranges for their stages at death.

\section{Discussion}

The major findings of this paper are that transection of motoneuron axons during the period of naturally occurring cell death results in an increase in the number of motoneurons in the lumbar LMC. This increase persists for at least 6 months following transection, but if the tadpole enters metamorphic climax during the postoperative survival period an extreme loss of motoneurons occurs. Similar results have been obtained following hindlimb amputation in other anuran species and generally have been interpreted in the context of the motoneuron's requirement for a survival factor that derives from the target. However, several aspects of the present results make it difficult to fit either the increase in motoneuron number or the subsequent decrease into such a context.

\section{Previous studies of motoneuron number following amputation}

Prestige (1967) suggested that Xenopus motoneurons respond to amputation of the innervated hindlimb in a manner dependent on their phase of development. The most immature (phase I) motoneurons are unaffected by limb removal. Phase II motoneurons die within 3-4 d of amputation for want of trophic support from the hindlimb. Phase III motoneurons are the most mature and die after their stores of the putative limb-derived trophic factor are depleted. The number of motoneurons surviving amputation thus would depend on the relative proportions of phase I, II, and III motoneurons present at the developmental stage in which amputation took place and the postoperative survival period. Prestige (1967) found that motoneuron number did increase 10-12\% (mean values for tadpoles operated on at stages 57 or 61 ) following amputations among tadpoles whose hindlimbs were removed after the period of massive cell death (stages 54-56; Hughes, 1961; Prestige, 1967). Among these animals, up to $75 \%$ of the motoneurons on the operated side were classified as undergoing chromatolysis, an aspect of the axon reaction. Another aspect of the axon 


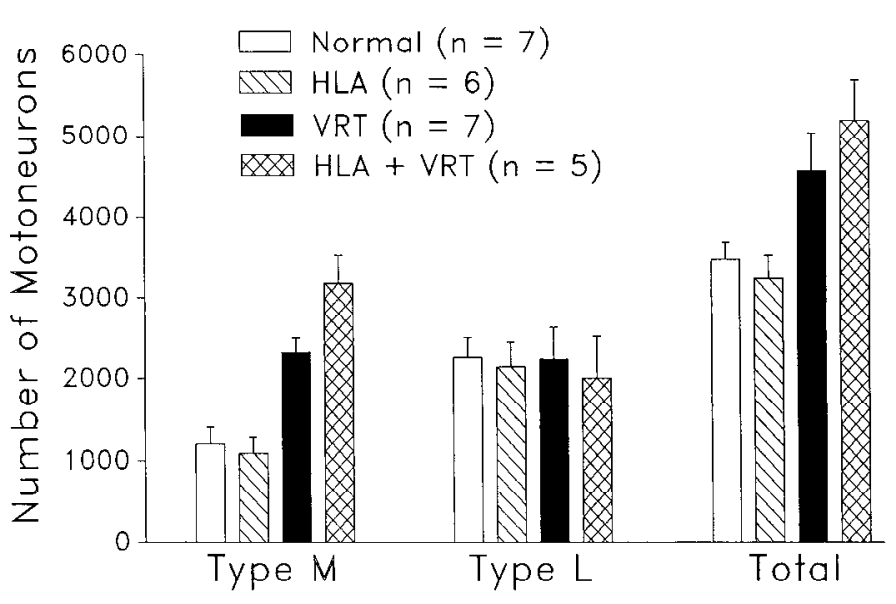

Figure 7. Motoneuron number in stage VIII tadpoles. Data are shown for normal tadpoles, tadpoles that had undergone unilateral hindlimb amputation 6-7 weeks previously $(H L A)$, tadpoles that had undergone unilateral transection of VRs 8-10 6-7 weeks previously (VRT), and tadpoles that had the hindlimb amputated on the same side on which VRs 8-10 were transected. Note the lack of effect of hindlimb amputation alone.

rcaction is swelling of the nuclcolus (Edström, 1959), which was used as the criterion for counting by Prestige. Because no correction factor for double counts was used, the possibility exists that the modest increases in motoneuron number seen in Xenopus may be an artifact of the counting procedure.

Beaudoin (1955) performed amputations in $R$. pipiens tadpoles at stages when the hindlimb is just being innervated. He concluded that motoneurons whose larget has been removed differentiate more slowly than normal motoneurons. Thus, these motoneurons do not become dependent on limb-derived factors at the same time as motoneurons on the unoperated side. Consequently, the process of naturally occurring cell death is retarded until differentiation proceeds to the stage in which the axotomized motoneurons are dependent on the target for survival. At this time, virtually all target-deprived motoneurons die. Decker (1978) extended Beaudoin's (1955) findings by performing amputations at several different stages after hindlimb innervation and, on the basis of these results, concluded that the response of $R$. pipiens motoneurons to loss of their target is, as in Xenopus, dependent on their stage of development [see also Kett and Pollack (1985) and Stebbins and Pollack (1986) for further elaboration of these results].

\section{Axotomy-induced increase in motoneuron number}

In the present study, an increase in motoneuron number was found following motoneuron axotomy. The stages when rhizotomy was effective in increasing motoneuron number corresponded to the stages of naturally occurring cell death (Farel, 1987). This correspondence implies that axotomy rescues motoneurons from the action of mechanisms that reduce motoneuron number. In chick, agents that block neuromuscular transmission appear to rescue all motoneurons from naturally occurring cell death (Pittman and Oppenheim, 1979). to determine whether axotomy is as effective in preventing motoneuron death in bullfrog as neuromuscular blocking agents are in chick requires experiments in which limb reinnervation is prevented in tadpoles that continue to develop during the postoperative survival period. 'Two tadpoles advanced from stages VI to VIII following VR ligation. Both these tadpoles had motoneuron numbers typical of stage VIII animals on the unoperated side and numbers typical of stage VI animals on the operated side. These preliminary results are consistent with the hypothesis that axotomy is rescuing all injured motoneurons from cell death.

The possibility that axotomy affects motoneuron proliferation is unlikely since repeated injections of ${ }^{3} \mathrm{H}$-thymidine through the postoperative survival period following rhizotomy fail to label any LMC motoneurons at stages in which an increase in motoneuron number is found (Farel and Bemelmans, 1986). The histolngical changes apparent in motoneurons on the operated side made them appear more differentiated than motoneurons on the unoperated side or those in normal animals (compare the numbers of type- $\mathrm{L}$ and -M motoneurons in Figs. 4 and 5). This finding is inconsistent with Beaudoin's (1955) suggestion that the increase in motoneuron number found following hindlimb amputation is due to delayed differentiation of motoneurons on the operated side.

In bullfrog, hindlimb amputation had no effect on motoneuron number or differentiation, in contrast to results obtained with other amphibian species. In bullfrog, then, removal of the target is not a sufficient condition for hyperplasia of the LMC. Conversely, experiments in which an increase in motoneuron number was found following transection or ligation of the VRs show that removal of the hindlimb is not a necessary condition for the increase in motoneuron number to be manifested. These experiments do not support the hypothesis that disconnection from the hindlimb is responsible for the transient increase in motoneuron number seen following hindlimb amputation.

\section{Axotomy-induced loss of motoneurons}

Motoneuron loss occurred only when the operated tadpole entered into metamorphic climax during the postoperative survival period. If motoneurons were dying because they had exhausted their stores of a limb-derived survival factor (Prestige, 1967), then one would expect motoneuron loss to be dependent on survival time. However, loss was independent of postoperative survival time, as evidenced by the fact that tadpoles rhizotomized at the same stage and allowed to survive for the same amount of time showed loss of motoneurons only if they advanced to stage XX. Further, operated tadpoles allowed to survive for up to 6 months showed no loss of motoneurons if they did not enter metamorphic climax.

By the time of their death, motoneurons had reformed connections with the hindlimb (Farel and Bemelmans, 1986), so it is doubtful that deprivation of contact with the target played a role in cell loss. Motoneuron loss also occurred when the VRs were transected and ligated, eliminating the possibility that motoneuron loss at metamorphic climax was dependent on a signal from the peripheral target.

Most of the tadpoles in which motoneuron loss was found had advanced beyond the stage of naturally occurring cell death at the time of rhizotomy. Thus, mechanisms operating during the period of massive cell death are unlikely to have acted to reduce motoneuron number after axotomy.

\section{Conclusion}

Ventral rhizotomy affects the number and histological appearance of spinal motoneurons, but these changes are not a consequence of depriving the motoneurons of access to putative survival factors supplied by the hindlimb. A more likely explanation of the present results is that the somatic reaction produced by axotomy disrupts developmental processes that would 
A
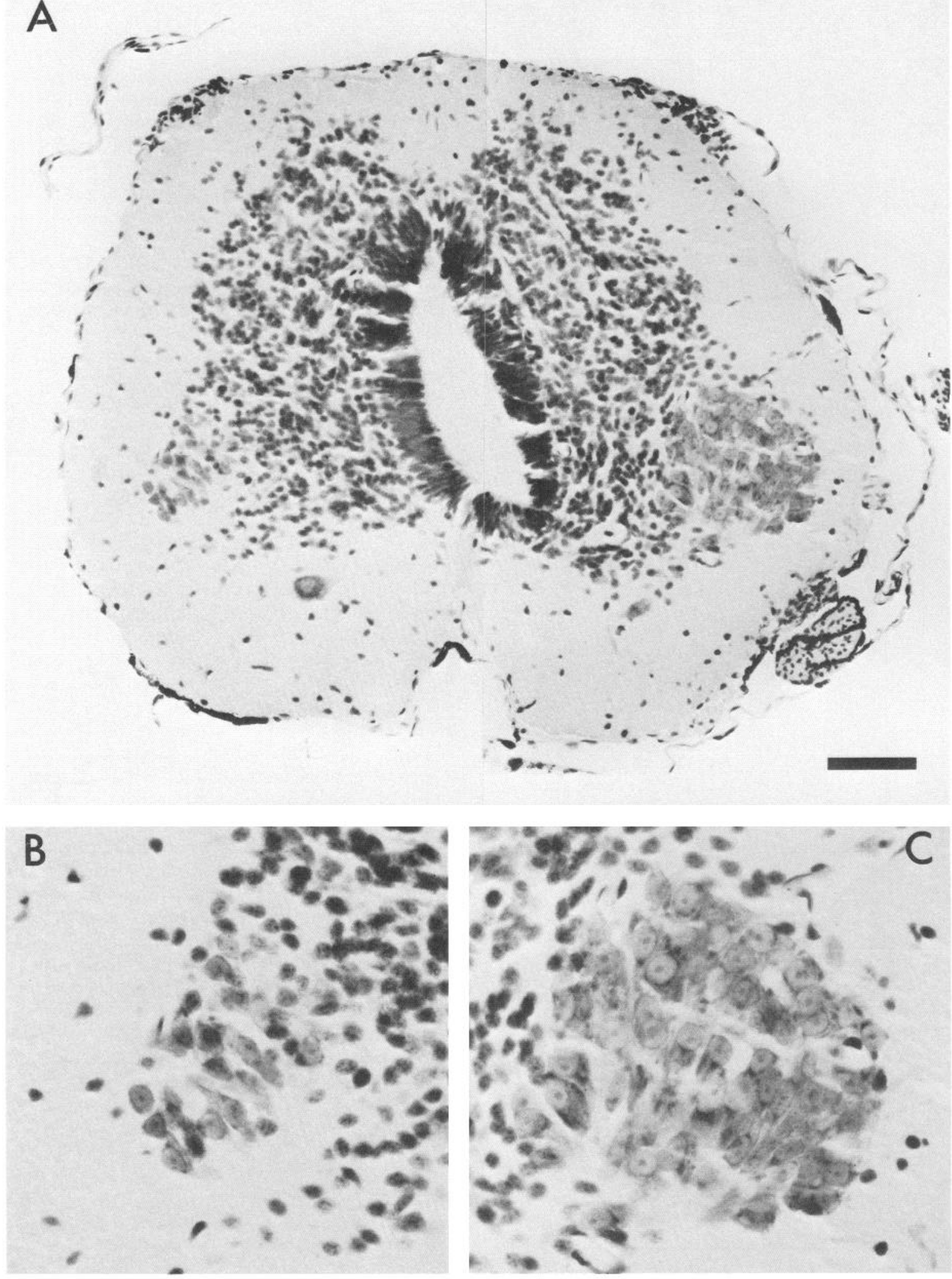

Figure 8. A, Low-power micrograph of a cross-section through the lumbar spinal cord of a stage VIII tadpole whose lumbar VRs were transected on the right side 6 weeks previously at stage VI. VRs 8 and 9 were ligated at the the time of transection. Note the hyperplasia on the operated side. $B, C$, Higher-power micrographs of the LMCs on the unoperated $(B)$ and operated $(C)$ sides. Scale bar: $A, 65 \mu \mathrm{m} ; B, C, 30 \mu \mathrm{m}$. 


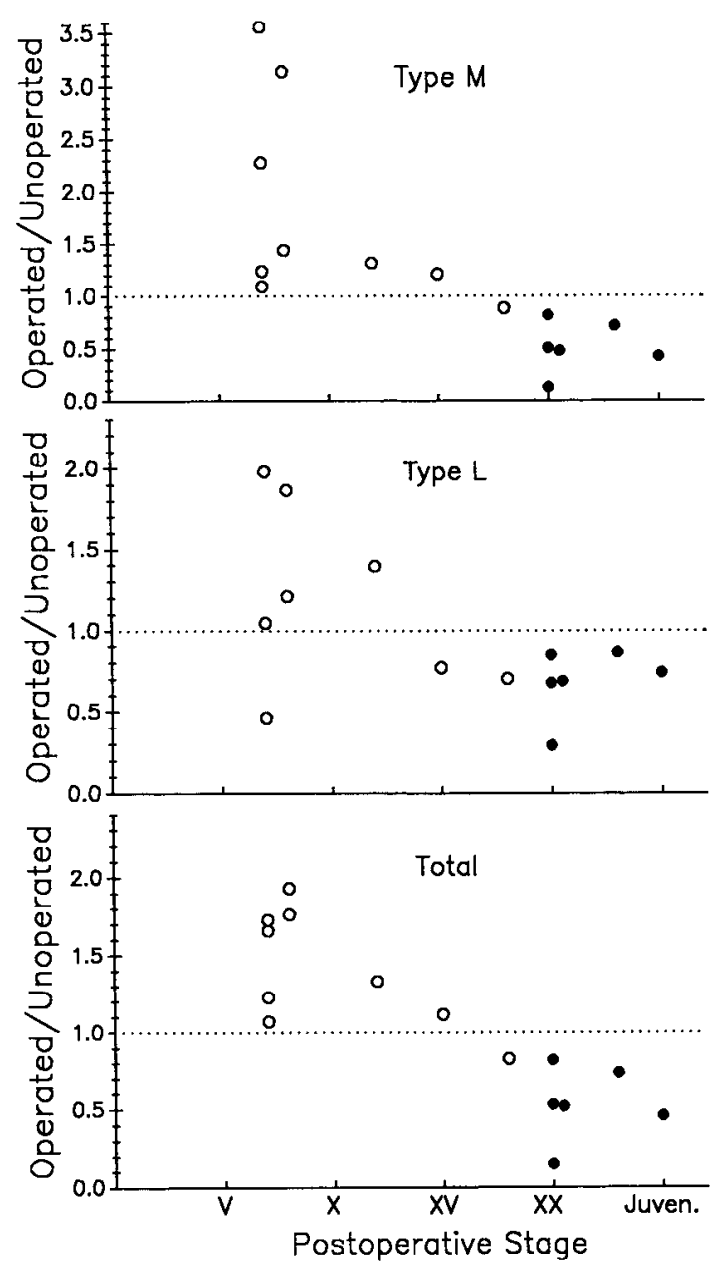

Figure 9. Ratio of motoneurons on the operated and unoperated sides of the spinal cord plotted against postoperative stage for tadpoles that had undergone transection of VRs 8-10 and ligation of VRs 8 and 9. Graphs are presented for type-M (top), type-L (center), and total (bottom) motoneurons. Filled circles represent animals that were operated on as tadpoles and killed after entering metamorphic climax. Open circles represent animals killed before climax.

normally reduce the number of motoneurons during the period of naturally occurring cell death (Prestige, 1967). Axotomy has profound effects on the metabolism (Sinicropi et al., 1982; Sinicropi and McIlwain, 1983), excitability (Farel, 1978, 1980), and morphology (Price and Porter, 1972; Rosenthal and Cruce, 1984) of adult frog motoneurons.

In chick, limb amputation leads to extensive depletion of the LMC (e.g., I Iamburger, 1934, 1958) during the period of naturally occurring cell death (Hamburger, 1975). Amputation in these experiments did not truncate motoneuron axons because the operations were performed before motor axons had invaded the hindlimb (Heaton, 1977). However, motor axons lacking a target may form a dense neuroma (Hamburger, 1958; Oppenheim et al., 1978) or continue their growth in abnormal directions (Tosney and Landmesser, 1984). To the extent that the normal export of substances synthesized in the soma is disrupted, motoneuron survival may be impaired (Hamburger, 1958, 1968).

In contrast to results obtained in other anuran species (see above), limb amputation in bullfrog tadpoles does not have a discernible effect on motoneuron number or histological ap- pearance. This discrepancy in results is not readily cxplicable if one assumes that amputation has its effects because it deprives motoneurons of access to a target-derived trophic substance. However, the consequences of axotomy are very variable among different classes of neurons (Lieberman, 1971; Watson, 1976), and this variability could well account for the differences in the effects of axotomy among the various species. For example, the severity of the axon reaction varies inversely with the distance from the cell body at which the axon is transected (McIlwain and Farel, 1979). Limb amputation in $R$. pipiens and $X$. laevis might remove a greater proportion of motoneuron axon length than does the same operation in the much larger bullfrog, and, consequently, the changes induced in motoneuron somata might be sufficient to protect them from the mechanisms of naturally occurring cell death.

The hypothesis that motoneuron number following ventral rhizotomy depends on aspccts of the axon reaction is unsatisfying in that the particular aspects of the axon reaction that are important cannot yet be specified. One promising avenue may be opened by recent findings (Schwartz and Kay, 1987; Martin et al., 1988) suggesting that, at least in certain situations, naturally occurring or programmed cell death depends on RNA and protein synthesis. Axotomy may prevent cell death by delaying or preventing the required synthetic activities.

To argue that aspects of the axon reaction protect motoneurons from naturally occurring cell death, one also has to assume either that the protective effect of the axon reaction continues after axons have regenerated to the hindlimb or that motoneurons are only susceptible to the mechanisms producing cell death during a certain period of their development. The survival of chick motoneurons until hatching when they have been protected through the period of naturally occurring cell death by neuromuscular blocking agents (Oppenheim, 1984) provides support for this second possibility.

Motoneurons whose axons have been previously transected may die at metamorphosis because of residual effects of the axon reaction combined with the stress entailed in the metamorphic process, perhaps associated with the precipitous rise in serum levels of thyroxine at climax (Regard et al., 1978; Mondou and Kaltenback, 1979). For example, frog motoncurons have receptors sensitive to the excitatory neurotransmitter agonist $N$-methyl-D-aspartate (McClellan and Farel, 1985; King et al., 1987). This agonist also has neurotoxic effects, which are more potent if the neuron is metabolically stressed (Novelli et al., 1988). Activation of these receptors, normally benign in the metamorphosing tadpole, may result in the death of a motoneuron that has been previously axotomized.

\section{References}

Abercrombie, M. (1946) Estimation of nuclear population from microtome sections. Anat. Rec. 94: 239-247.

Beaudoin, A. L. (1955) The development of latcral motor column cells in the lubo-sacral cord in Rana pipiens. Anat. Rec. 121:81-96.

Cruce, W. L. R. (1974) The anatomical organization of hindlimb motoneurons in the lumbar spinal cord of the frog, Rana calesbeiana, J. Comp. Neurol. 153: 59-76.

Decker, R. S. (1978) Retrograde responses of developing lateral motor column neurons. J. Comp. Neurol. 180: 635-660.

Detwiler, S. R. (1933) Experimental studies upon the development of the amphibian nervous system. Biol. Rev. 8: 269-310.

Dickerson, M. C. (1969) The Frog Book, Dover, New York.

Edström, J.-E. (1959) Ribonucleic acid changes in the motneurons of the frog during axon regeneration. J. Neurochem. 5:43-49.

Farel, P. B. (1978) Reflex activity of regenerating frog spinal motoneurons. Brain Res. 158: 331-341. 
Farcl, P. B. (1980) Sclcctive synaptic changes following spinal motoneuron axotomy. Br. Res. 189: 67-77.

Farel, P. B. (1987) Motoneuron number in the lumbar lateral motor column of larval and adult bullfrogs. J. comp. Neurol. 261: 266-276.

Farel, P. B., and S. E. Bemelmans (1985) Specificity of motoneuron projection patterns during development of the bullfrog tadpole (Rana catesbeiana). J. Comp. Neurol. 238: 128-134.

Farel, P. B., and S. E. Bemelmans (1986) Restoration of neuromuscular specificity following ventral rhizotomy in the bullfrog tadpole, Rana catesbeiana. J. Comp. Neurol. 254: 125-132.

Farel, P. B., and S. E. Wray (1989) Regenerative specificity of motor axons when reinnervation is partially suppressed. J. Neurobiol. 20: 69-80.

Gaupp, E. (1896-1904) A. Ecker's und R. Weidersheim's Anatomie des Froches, F. Vieweg, Braunschweig.

Grafstein, B. (1975) The nerve cell body response to axotomy. Exper. Neurol. 48: 32-51.

Hamburger, V. (1934) The effects of wing bud extirpation on the development of the central nervous system in chick embryos. J. Exp. Zool. 68: 449-494.

Hamburger, V. (1958) Regression versus peripheral control of differentiation in motor hypoplasia. Am. J. Anat. 102: 365-410.

Hamburger, V. (1968) Discussion. In Growth of the Nervous System, Ciba Foundation Symposium, G. E. W. Wolstenholme and M. O'Connor, eds., pp. 121-122, Little, Brown, Boston.

Hamburger, V. (1975) Cell death in the development of the lateral motor column of the chick embryo. J. Comp. Neurol. 160: 535-546.

Heaton, M. B. (1977) Retrograde axonal transport in lateral motor neurons of chick embryo prior to limb bud innervation. Dev. Biol. 58: $421-427$.

Hughes, A. (1961) Cell degeneration in the larval ventral horn of Xenopus laevis (Daudin). J. Embryol. Exp. Morph. 9: 269-284.

Kett, N. A., and E. D. Pollack (1985) Retention of lateral motor column neurons during the phase of rapid cell loss after limb amputation in Rana pipiens tadpoles. J. Exper. Zool. 236: 59-66.

King, A. E., E. Cherubini, and A. Nistri (1987) A study of amino acidactivated currents recorded from frog motoneurones in vitro. Neurosci. Lett. 76: 179-184.

Konigsmark, B. W. (1970) Methods for the counting of neurons. In Contemporary Research Methods in Neuroanatomy, W. J. H. Nauta and S. O. E. Ebbesson, eds., pp. 315-339. Springer-Verlag, New York.

Landmesser, L. T. (1980) The generation of neuromuscular specificity. Annu. Rev. Neurosci. 3: 279-302.

Letinsky, M. S. (1974) The development of nerve-muscle junctions in Rana catesberiana tadpoles. Dev. Biol. 40:129-153.

Lieberman, A. R. (1971) The axon reaction: A review of the principal features of perikaryal response to injury. Int. Rev. Neurobiol. 14:49124.

Martin, D. P., R. E. Schmidt, R. S. DiStefano, O. H. Lowry, J. G. Carter, and E. M. Johnson, Jr. (1988) Inhibitors of protein synthesis and RNA synthesis prevent neuronal death caused by nerve growth factor deprivation. J. Cell Biol. 106: 829-844.

May, R. M. (1933) Modifications observées dans la moelle epiniere dans des cas de greffe en surnombre, ou d'ablation d'une ébauche du patte posteriéure chez l'embryon de l'Anoure, Discoglossus pictus Otth. Comptes rendus heb. des séances Acad. Scien. 196: 567-569.

McClellan, A. D., and P. B. Farel (1985) Pharmacological activation of locomotor patterns in larval and adult frog spinal cords. Br. Res. 332: 119-130.

McIlwain, D. L., and P. B. Farel (1979) Initiation and time course of mitosis of non-neuronal cells after spinal motoneuron axotomy. $\mathrm{Br}$. Res. 178: 519-528.

Mondou, P. M., and J.C. Kaltenbach (1979) Thyroxine concentrations in blood serum and pericardial fluid of metamorphosing tadpoles and of adult frogs. Gen. Comp. Endocrinol. 39: 343-349.

Novelli, A., J. A. Reilly, P. G. Lysko, and R. C. Henneberry (1988) Glutamate becomes neurotoxic via the $\mathrm{N}$-methyl-d-aspartate receptor when intracellular energy levels are reduced. Br. Res. 451: 205-212.
Oppenheim, R. W. (1981) Neuronal cell death and some related regressive phenomena during neurogenesis: A selective review and progress report. In Studies in Developmental Neurobiology: Essays in Honor of Viktor Hamburger, W. M. Cowan, ed., pp. 74-133, Oxford U.P., New York.

Oppenheim, R. W. (1984) Cell death of motoneurons in the chick embryo spinal cord. VIII. Motoneurons prevented from dying in the embryo persist after hatching. Dev. Biol. 101: 35-39.

Oppenheim, R. W., I.-W. Chu-Wang, and J. L. Maderdrut (1978) Cell death of motoneurons in the chick embryo spinal cord. III. The differentiation of motoneurons prior to their induced degeneration following limb removal. J. Comp. Neurol. 177: 87-112.

Pittman, R., and R. W. Oppenheim (1979) Cell death of motoneurons in the chick embryo spinal cord. IV. Evidence that functional neuromuscular interaction is involved in the regulation of naturally occurring cell death and the stabilization of synapses. J. Comp. Neurol. 187: $425-446$.

Prestige, M. C. (1967) The control of cell number in the lumbar ventral horns during the development of Xenopus laevis tadpoleps. J. Embryol. Exp. Morph. 18: 359-387.

Price, D. L., and K. R. Porter (1972) The response of ventral horn neurons to axonal transection. J. Cell Biol. 53: 24-37.

Purves, D., and J. W. Lichtman (1985) Principles of Neural Development, Sinauer, Sunderland, MA.

Regard, E., A. Taurog, and T. Nakashima (1978) Plasma thyroxine and triiodothyronine levels in spontaneously metamorphosing Rana catesbeiana tadpoles and in adult anuran amphibia. Endocrinology 102: 674-684.

Rosenthal, B. M., and W. L. R. Cruce (1984) Contralateral motoneuron dendritic changes induced by transection of frog spinal nerves. Exp. Neurol. 85: 565-573.

Schwartz, L. M., and B. K. Kay (1987) De novo transcription and translation of new genes is required for the programmed death of the intersegmental muscles of the tobacco hawkmoth, Manduca sexta. Soc. Neurosci. Abstr. 13: 8 .

Shorey, M. L. (1909) The effect of the destruction of peripheral areas on the differentiation of the neuroblasts. J. Exp. Zool. 7: 25-63.

Sinicropi, D. V., and D. L. McIlwain (1983) Changes in the amounts of cytoskeletal proteins within the perikarya and axons of regenerating frog motoneurons. J. Cell Biol. 96: 240-247.

Sinicropi, D. V., K. Michels, and D. L. McIlwain (1982) Acetylcholinesterase distribution in axotomized frog motoneurons. J. Neurochcm. 38: 1099-1105.

Sperry, D. G. (1987) Relationship between natural variations in motoneuron number and body size in Xenopus laevis: A test for size matching. J. Comp. Neurol. 264: 250-267.

Stebbins, C. A., and E. D. Pollack (1986) Neuron number and asynchronous hindlimb development during the period of profound cell loss in the lateral motor column of Rana pipiens larvae. J. Exp. Zool. 237: 79-85.

Taylor, A. C., and J. J. Kollros (1946) Stages in the normal development of Rana pipiens. Anat. Rec. 94: 7-24.

Tosney, K. W., and L. T. Landmesser (1984) Pattern and specificity of axonal outgrowth following varying degrees of chick limb bud ablation. J. Neurosci. 4: 2518-2527.

Viparina, S., and J. J. Just (1975) The life period, growth and differcntiation of Rana catesbeiana larvac occurring in nature. Copeia nv: 103-109.

von Gudden, B. A. (1870) Experimentaluntersuchungen über das peripherische und centrale Nervensystem. Arch. Psychiatr. 2: 693-723.

Vulpian, A. (1868) Influence de l'abolition des fonctions des nerfs sur la région de la moelle épiniére qui leur donne origine. Examen de la moelle épinière dans des cas d'amputation d'ancienne date. Arch. Physiol. Norm. Pathol. 1: 443-448.

Watson, W. E. (1976) Cell Biology of Brain, Wiley, New York. 